\title{
O corpo que nada esquece: sensibilidade, percepção e memórias corporais
}

\author{
The body that nothing forgets: sensibility and bodily \\ memories
}

\section{El cuerpo que nada olvida: sensibilidad y recuerdos corporales}

\author{
iD Yara Aparecida Couto \\ Universidade Federal de São Carlos \\ São Carlos, SP, Brasil \\ E-mail: yaracouto@ufscar.br \\ iD (9) Daniela Frizzon Zamboni \\ Universidade Federal de São Carlos \\ São Carlos, SP, Brasil \\ E-mail: dfz_1@hotmail.com
}

\begin{abstract}
Resumo: O ser humano, ao longo da vida, pouco explora de suas experiências corporais, sua sensibilidade às emoções e a expressão de seus desejos. Este estudo objetivou investigar o impacto do processo de conscientização do corpo pelas práticas corporais holísticas (PCH). Tais práticas integram o campo físico, emocional, mental e espiritual nas esferas do fazer, perceber, sentir, imaginar e criar. Detalhamos o estudo de caso realizado com uma pessoa participante que vivenciou nas $\mathrm{PCH}$ a percepção de si mesma e o enfrentamento de seus conflitos. As vivências corporais encorajaram a reflexão pessoal acerca da confiança nos momentos de repulsa e baixa autoestima, bem como favoreceram a percepção das memórias corporais, da sensibilidade a fim de reverberar o pertencimento e a autoria de si.
\end{abstract}

Palavras-chave: Práticas Corporais Holísticas. Percepção. Sensibilidade. 


\begin{abstract}
The human being in his life little explores his experiences of bodily life, his sensitivity to emotions and the expression of his desires. This study aimed to investigate the impact of the body awareness process by holistic body practices (SHP). Such practices integrate the physical, emotional, mental, spiritual field in the spheres of doing, perceiving, feeling, imagining and creating. We detail the case study conducted with the participant who experienced in the SHP the perception of themselves and the coping with their conflicts. The bodily experiences encouraged personal reflection about trust in moments of revulsion and low selfesteem, as well as favored the perception of body memories, sensitivity in order to reverberate belonging and self-authorship.
\end{abstract}

Keywords: Holistic Body Practices. Perception. Sensitivity.

Resumen: El ser humano en su vida poco explora sus experiencias de vida corporal, su sensibilidad a las emociones y la expresión de sus deseos. Investigamos el impacto del proceso de conciencia corporal por prácticas integrales del cuerpo (SHP). Tales prácticas integran el campo físico, emocional, mental, espiritual en las esferas de hacer, percibir, sentir, imaginar y crear. Detallamos el estudio de caso realizado con La persona participante que experimentó en el SHP la percepción de sí misma y la afrontación de sus conflictos. Las experiencias corporales alentaron la reflexión personal sobre la confianza en momentos de repulsión y baja autoestima, así como favorecieron la percepción de los recuerdos corporales, la sensibilidad para reverberar la pertenencia y la autoautoría.

Palabras-clave: Prácticas Corporales Holísticas. Percepción. Sensibilidad.

Submetido em: 06-11-2019

Aceito em: 26-10-2020 
O corpo que nada esquece: sensibilidade, percepção e memórias corporais Yara Aparecida Couto • Daniela Frizzon Zamboni

\section{Introdução}

Os processos de mudanças deste século impõem um ritmo desenfreado, acelerado e repetitivo que nos robotizam e nos tornam tão lógicos a ponto de, muitas vezes, quando no estado de limitação em que nos encontramos, também restringimos o movimento, a imaginação, a inteligência, os sentimentos, enquanto enfraquecemos também as sensações e percepções de nós mesmos e do mundo.
A verdade é que sequer há espaço para sentirmos, para sermos o que somos além da cognição: sentimento, emoção, afeto. A Arte e seus aspectos - sensação, intuição, expressão, criação - são ignorados, restringindo nossas possibilidades de entendi- mento do mundo, da vida, da realidade, das coisas, de nós mes- mos (1) (OSTETTO, 2006, p. 155).

Estamos em épocas difíceis. Carecemos de sintonia com aspectos sutis e criativos que nos convidem a viver o presente, pois, quando nos deparamos com circunstâncias de difíceis resoluções e, com certeza, esclarecemos que cada pessoa tem o seu entendimento do que é difícil para si, o corpo experimenta, registra e guarda tais dificuldades. Até esse ponto, problema algum com isso. O fato é que quando ocorrem sintomas que interferem na saúde e no bem-estar, geralmente isso acaba por ferir as relações estabelecidas no entorno da pessoa, inclusive consigo mesma, acarretando em redução da sua qualidade de vida.

Circundante às ideias pelo cerne do sentir e ser humano integrado aos aspectos visíveis e outros não palpáveis, mas nem por isso menos importantes, este trabalho de investigação de um estudo de caso, conduzido pelas práticas corporais holísticas $(\mathrm{PCH})$, traz como possibilidade de realização das atividades corporais propostas juntamente à aluna participante. Deste modo, o nosso objetivo foi investigar o impacto do processo de conscientização do corpo mediante as PCH. Além disso, este artigo teve como foco 
O corpo que nada esquece: sensibilidade, percepção e memórias corporais Yara Aparecida Couto • Daniela Frizzon Zamboni

o corpo mediado pelos processos vividos, suas memórias corporais e como isto afeta a relação estética e sensível do corpo em seu entorno e consigo mesmo.

\section{Percepção e sensibilidade estética}

A palavra percepção tem sido tema de muitos textos, artigos, eventos e discursos acadêmicos. Na última edição da $33^{\mathrm{a}}$ Bienal de São Paulo (2018), por exemplo, (4) Rafael Paniagua trouxe, de maneira profunda, a reflexão de que a percepção dá forma ao mundo. No entanto, o autor alerta para o fato de que se nos prendemos a relações fundamentadas no interesse egoísta, na insegurança afetiva, ou quando ficamos distantes da empatia, se preferimos a indiferença, o isolamento e a alienação, estamos eliminamos a percepção do mundo, da natureza e de nós mesmos. O resultado é a vida e os corpos assumindo outra configuração e tornando-se estranhos, ausentes de experiências, até chegarmos ao ponto que não nos reconhecemos.

Desse modo, (5) Berge (1988) afirma que o espontâneo surge quando o corpo torna-se consciente de cada estrutura que o comunica com o mundo, assim também como quando toma consciência da respiração, dos sons, dos movimentos e sabe ver no outro a graça viva do gesto. Caso contrário, seguimos na mecanicidade que esvazia o sentido das coisas e, consequentemente, mortificamos nossa percepção, expressividade, criatividade e imaginação.

Consideramos fundamental esboçar algumas considerações sobre a sensibilidade e sua inefável contribuição para nos ajudar no trabalho de busca pela harmonia e bem-estar que iremos percorrer neste texto. As afirmações de (2) Hillman (2010) sobre sensibilidade compreendem-na como um elo que conecta a totalidade da pessoa e a estética, como o mundo é apresentado a cada pessoa desde o momento de seu nascimento. Portanto, ser sensível às coisas é também compreender o que é belo no outro e no mundo, uma prazerosa elevação do estado de felicidade. $O$ 
O corpo que nada esquece: sensibilidade, percepção e memórias corporais Yara Aparecida Couto • Daniela Frizzon Zamboni

mesmo autor também sustenta a ideia de que são tantas as possibilidades com as quais podemos qualificar o mundo, aguçando a nossa percepção, ampliando nossa intimidade com os sentidos para reformular as respostas estéticas que se fazem vivas nas formas, cores, sabores, sons, tons e gestos, sempre em conexão com a natureza. Desta maneira, nós podemos orientar nossas percepções para perceber o mundo, as coisas e nós mesmos de um modo diferente, mais amplo e carregado de sentidos e significado.

Segundo (3) Hermann (2005), a palavra estética deriva "do grego", aisthesis, aistheton e significa sensação, sensível, percepção pelos sentidos ou conhecimento sensível-sensorial. (2) Hillman (2010) nos fala do coração como o órgão da percepção estética. Segundo este mesmo autor, é no processo respiratório, ao inspirar, que nós conduzimos o mundo para dentro de nós, seja na surpresa, no encanto, no susto. Trata-se da reação estética à imagem apresentada, portanto, o coração abriga a imaginação e faz a conexão primordial com aquilo que nos cerca. No campo da subjetividade, a percepção estética nos transporta a lugares que o conhecimento científico por si só não alcançaria, pois permite potencializar a imaginação necessária ao processo criativo. Desse modo, encontramos na imaginação e na expressão a possibilidade de libertar o corpo aprisionado no esquecimento de como movimentar-se e encorajar a percepção de si mesmo. É assim que anelamos um novo caminho para enfrentar os desconfortos - sejam de ordem física, energética ou emocional. Desta forma, queremos dizer que toda expressividade nasce na imaginação e com ela é possível carregar significado aos movimentos que realizamos no nosso cotidiano, quer seja nas atividades profissionais, na comunicação com o outro ou no entendimento de nós mesmos.

\section{Práticas corporais holísticas e memórias corporais}

Sentindo-nos imersos nesse deslumbre sobre o sensível e apontamos como possibilidade de ampliar o prisma sob os hori- 
O corpo que nada esquece: sensibilidade, percepção e memórias corporais Yara Aparecida Couto • Daniela Frizzon Zamboni

zontes do autoconhecimento, para isso alguns pontos do trabalho holístico merecem destaque.

Há milênios a medicina tradicional chinesa considera fundamental o controle da energia vital Qi (chi), reguladora e equilibradora entre as esferas que compreendem o universo, o ser humano e a natureza. Quando o campo Qi está desequilibrado é através da meditação que ocorre a busca pela sua estabilidade, harmonia e reflexão'. Consideramos esse viés da cultura oriental, na tentativa de reconhecer sua influência na compreensão do holismo, e assim, lançarmos um olhar, sob a ótica das PCH, em relação ao trabalho prático e individualizado que o seu alcance proporcionou, especialmente a este artigo.

O termo holístico é relativo ao holismo que vem do grego holos, integra o fenômeno de globalidade e, segundo (6) Lorenzetto; Matthiesen (2008), significa "inteiro" ou "todo". No entanto, foi relativamente recente a disseminação dos conceitos holísticos no ocidente junto à explosão do movimento da contracultura nas décadas de 1950 e 1960. Momento em que as pessoas buscavam por algo contestador dos padrões socioculturais da época, inerentes à política, educação, artes e relações sociais (7) (Roszak, 1972). Um pouco mais tarde, nos anos 1980, germinava o contato da sociedade com práticas corporais advindas do oriente como, por exemplo, o yoga, o tai chi chuan, a meditação, entre outros. Enquanto isso, ocorria o entrosamento de técnicas e saberes disseminados no ocidente, como Pilates, bioenergética, antiginástica, eutonia, método Feldenkrais, entre outros (8) (COLDEBELLA, 2002; (6) LORENZETTO; MATTHIESEN, 2008).

Os autores (9) Cesana \& Souza Neto (2008) apontam peculiaridades dessas práticas, como a possibilidade de sustentar críticas ao modelo cartesiano de corpo, "com uma mudança no paradigma da saúde e da aceitação de conhecimentos "não científicos", não fundamentados em métodos e comprovações quantitativas, o que alguns autores chamam de "pós-modernidade" (p. 467). Com isso,

1 Referência sobre a obra do Mestre Lao-Tsé. Tao te Ching: o livro do caminho e da virtude. Disponível em: https://edisciplinas. usp.br/pluginfile.php/3402951/mod_resource/content/1/31LaoTse_TaoTeChing.pdf. 
O corpo que nada esquece: sensibilidade, percepção e memórias corporais Yara Aparecida Couto • Daniela Frizzon Zamboni

expomos os valores norteadores das práticas holísticas, os quais têm como base a visão de totalidade perante os fenômenos que reintegram natureza e as dimensões do ser humano no campo físico, mental, emocional e espiritual (5) (BERGE, 1988; (10) FERREIRA, 2000; (8) COLDEBELLA, 2002; (6) LORENZETTO; MATTHIESEN, 2008).

De um modo geral, essas técnicas orientais e ocidentais contemplam movimentos alternativos às práticas comuns que priorizam a força e a competição, que, inclusive, até podem remeter a um tipo de adestramento forçado (11) (BERTHERAT, 1977). Sem dúvida, há quem opte por esse tipo de prática e tudo bem. No entanto, há pessoas que se identificam e preferem as práticas holísticas. Segundo (12) Impolcetto (2013), elas garantem a presença de elementos como: "a percepção e individualização do movimento, a sensibilização, contato com o natural, o fazer junto, a busca do Ser [...] e podem promover experiências e sensações [...] como relaxamento, autoconhecimento etc" (p. 11-12). Nesse sentido (10), Ferreira (2000) afirma que tais práticas conferem "lentidão, suavidade, concentração, consciência corporal, respiração lenta e profunda. Essas particularidades podem desencadear uma nova maneira de descobrir, pensar, sentir e vivenciar o corpo" (p. 58).

As PCH desenvolvidas ao longo da elaboração deste estudo de caso encorajam-nos a adentrarmos o universo da subjetividade e acessar os movimentos adormecidos e despertar para novas descobertas sobre o próprio corpo.

Um fator indissociável a essas questões é o que cada acontecimento e sensação vivenciada pela pessoa, de acordo com o seu entorno, irão construir e desconstruir o modo dela sentir, movimentar e até mesmo se posicionar diante dos seus conflitos. Sobre as sensações, únicas e peculiares a cada corpo, (13) Leloup (2002) traz o aspecto das memórias corporais. Para o autor um mesmo fato ocorrido é registrado em pensamento, coração e carne ${ }^{2}$ :

20 autor transmite a ideia de "corpo encarnado", de modo a considerar as tensões apreendidas em determinada região do corpo e a partir daí as modificações sucedidas em todo o corpo (13) (LELOUP, 2002). 
O corpo que nada esquece: sensibilidade, percepção e memórias corporais Yara Aparecida Couto • Daniela Frizzon Zamboni

O corpo é nossa memória mais arcaica. Nele, nada é esquecido. Cada acontecimento vivido [...] deixa no corpo sua marca profunda. [...] Por exemplo, podemos perdoar com o coração. Mas o corpo, frequentemente, é o último que perdoa. Nossa reação diante de tal ou qual pessoa que nós perdoamos com nossa mente ou com nosso coração, trai a não-confiança estabelecida em nosso corpo (13) (LELOUP, 2002, p. 15).

Portanto, além de considerar sensações encontradas nos pensamentos e sentimentos, também é preciso relacioná-las com o físico a fim de descobrir onde e como o corpo se retraiu, sofreu e guardou a não confiança dessa comunicação estabelecida na relação consigo mesmo ou com o outro, muitas vezes de forma inconsciente. Segundo (11) Bertherat (1977), nossa arquitetura corporal nunca esquece nada e, a partir disso, o acesso a essas memórias estabelece uma tênue relação no trabalho corporal, pois o indivíduo começa a dar-se conta dos movimentos que ele realiza ou não, ou que se esqueceu de como realizar.

Encontramos na literatura considerações tanto de (5) Berge (1988), (14) Vishnivetz (1995), (13) Leloup (2002), (6) Lorenzetto; Matthiesen (2008) quanto de (15) Jung (2011) de que a doença é a manifestação das consequências de alguma desordem no estado físico, orgânico, emocional e/ou energético do indivíduo, portanto, é fundamental considerar que os estados relativos às questões emocionais e psíquicas merecem ênfase tanto quanto as abordagens corporais. Desse modo, as PCH dialogam com métodos terapêuticos corporais, como, por exemplo, Pilates, Antiginástica, Rolfing, entre muitos outros, cujas abordagens prezam a reconciliação no corpo com suas memórias vividas, emoções e pensamento, pois, longe da neutralidade ou objetividade, permite explorar o desconhecido pela atenção à sensação, intuição, sentimento e pensamento (15) (JUNG, 2011).

Em sua época, a psicopedagoga (5) Berge (1988) já alertava para o fato de que a grande maioria das pessoas não se dá conta de que o maior equívoco é fragmentar atividades corporais dos es- 
O corpo que nada esquece: sensibilidade, percepção e memórias corporais Yara Aparecida Couto • Daniela Frizzon Zamboni

tados de alma ${ }^{3}$ e não lhes conceder o mesmo valor e, consequentemente, surgem compensações que ferem o físico e repercutem sobre o caráter, dando espaço para a timidez, desencorajando a confiança em si mesmo e nas demais pessoas.

Segundo (16) Levine (1999), a experiência individual e os sentidos estão relacionados pela combinação dos elementos sensação, imagem, comportamento, afeto e significado. Porém, os sentidos podem sofrer uma sobrecarga perceptiva que, segundo o mesmo autor, interfere na relação do sujeito com suas sensações e significados. Então, o entendimento de si mesmo, do outro e do mundo pode em algum ponto minimizar os potenciais criativos, imaginativos e o estado de felicidade da pessoa. Para poder amenizar os efeitos que podem repercutir sobre as relações indissociáveis do corpo e suas propriedades tanto anatômicas quanto emocional e energética, (17) Motta (2003) sugere trabalhar com o movimento corporal a fim de compreender o sentido e significado para as ações, sensações e relacionar com os desejos e pensamentos inerentes à realidade de cada um de nós.

Seguindo os processos existenciais do sujeito, buscamos investigar, seja pela ausência ou esquecimento do movimento, seja pela presença consciente do que o corpo é capaz de reconhecer, se é possível identificar bloqueios corporais manifestados na pessoa em sua estreita relação entre desejos e frustrações. Dessa forma, surge a possibilidade de transformar seus sintomas e assim potencializar as ferramentas que a pessoa usufrui para enfrentar os desafios no cotidiano familiar, profissional, social e pessoal.

\section{Procedimentos metodológicos}

Escolhemos um estudo de caso para discorrer sobre as abordagens corporais e o seu impacto no processo de (re)conheci-

\footnotetext{
3 Estados de alma: segundo (15) Jung (2011), a alma é indissolúvel ao corpo e assim como a personalidade, ela é uma realidade vivida psiquicamente no inconsciente e se manifesta através de símbolos. De acordo com o escritor (2) Hillman (2010) os estados de alma abrangem uma dimensão que transcende o entendimento de vida inerente a cada um de nós e potencializa os aspectos ligados ao espírito, mente, coração, essência, propósito, coragem, ética, moralidade, sabedoria, morte, virtude e fé.
} 
O corpo que nada esquece: sensibilidade, percepção e memórias corporais Yara Aparecida Couto • Daniela Frizzon Zamboni

mento do sujeito, considerando suas memórias corporais em um ambiente rico em movimentos, emoções, criatividade e reflexões dessa experiência acerca de sua própria realidade.

A intervenção foi realizada em uma academia do município de São Carlos-SP no período contínuo de um mês, no ano de 2017. Este trabalho foi submetido ao Comitê de Ética e Pesquisa (CEP4), e para o termo de consentimento livre e esclarecido (TCLE) recolhemos a assinatura tanto da instituição quanto da aluna participante.

As vivências corporais ocorreram em quinze encontros com duração de noventa minutos. Optamos por explorar as PCH como possibilidade de condução das atividades corporais propostas juntamente à aluna participante deste estudo de caso. Logo abaixo detalhamos as características presentes na abordagem com as $\mathrm{PCH}$ :

- tomar consciência da respiração a fim de tranquilizar a ansiedade, como também relaxar o corpo para propiciar maior atenção às sensações corporais;

- possibilitar a emoção aflorar entre sistema musculoesquelético, pensamento, ação, sentimento e a realização de diversos movimentos e posições pelo chão, interagindo com objetos, a fim de despertar maior conscientização corporal, como, por exemplo, fitas, tecido, bastão, bola, corda, elementos da terra como folhas, sementes e argila;

- despertar memórias corporais através do tato, como, por exemplo, vendar os olhos e caminhar sobre elementos da natureza assim como trazer à tona as sensações de dançar livremente pelo espaço, deixando conduzir-se pela música;

- possibilitar processos reflexivos perante as experiências de (re)descoberta para sustentar os pilares do autoconhecimento (inteligência emocional, tranquilidade e harmonia).

A experiência com a percepção foi consolidada em três momentos que se complementaram: $1^{\circ} \mathrm{o}$ contato com uma proposta

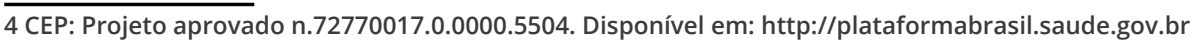


O corpo que nada esquece: sensibilidade, percepção e memórias corporais Yara Aparecida Couto • Daniela Frizzon Zamboni

de introspecção; $2^{\circ}$ a interação da aluna participante com objetos palpáveis para que ela expressasse sua identidade; $3^{\circ}$ reflexões sobre o elo das memórias corporais com as percepções que o ambiente proporcionou. Cada observação captada nos diálogos entre a pesquisadora e a aluna participante, assim como os depoimentos dela, foram estruturados em notas de campo (NC), também as atividades realizadas foram registradas por imagens.

\section{Resultados}

Acreditamos firmemente que as relações humanas apresentam-se mais favoravelmente pelo cuidado do outro, no modo que pronunciamos a nossa fala, no direcionamento do nosso olhar, no toque e gestos que vislumbram total entrega, tanto daquele que cuida como de quem recebe os cuidados. Nesse sentido, para (18) Couto (2010), trata-se da linguagem corporal que caracteriza e estabelece as possibilidades do sujeito e impulsiona diversos cenários, por exemplo, o ambiente criativo, colorido, musical, rítmico, dançante, repleto de movimento e trocas, interligando a intenção à percepção e aos sentimentos que afloram no modo como cada um se relaciona com o mundo.

Sendo assim, este estudo se fundamentou na condução das PCH para construir novas percepções, sentidos e significados, além de ser uma ferramenta facilitadora para acessar as memórias corporais, na perspectiva das experiências vivenciadas pela aluna participante, e, assim, auxiliar no seu processo de autoconhecimento.

As PCH proporcionaram sentir a percepção sutil da respiração, o toque sensível, o realinhamento do eixo corporal gravitacional; bem como acessar a subjetividade das sensações, as quais foram identificadas nos enredos com os elementos da terra, fantasias e imaginação, durante e após os processos criativos e expressivos; além dos pensamentos e reflexões acerca da própria realidade da aluna participante. A partir desse material foram elencados os pontos que mereceram destaques neste trabalho de investigação. 
O corpo que nada esquece: sensibilidade, percepção e memórias corporais Yara Aparecida Couto • Daniela Frizzon Zamboni

No momento inicial, os aspectos com a predominância de ações negativas ficaram evidentes nos relatos de vergonha e baixa autoestima como, por exemplo, registrado nas NC em diversos diálogos entre a pesquisadora e a aluna participante: "Sua reação foi "ah, você quer me expor ao ridículo!" (NC7); "Tenho vergonha, dificuldade de falar e movimentar" (NC13). Assim como o teor negativo para consigo mesma e a falta de confiança em si:

[...] não vou acertar fazer isso, jamais vou ter a flexibilidade como a sua (NC2);

[...] Sempre fui meio tímida. Sempre me achei o patinho feio. Não mudei muito, continuo tímida e me achando o patinho feio (NC9);

[...] Fiquei desmotivada, desesperada porque não havia conseguido emagrecer (NC12).

Nessa perspectiva, nota-se características minimizadoras daqueles que não vivem bem consigo mesmos e condicionam-se à passividade, "falta-Ihes ânimo, força, desencorajam-se depressa, têm as mãos moles. Sua respiração é lenta, pesada" (5) (BERGE, 1988 , p. 80). Os relatos transcritos nas NC trouxeram informações que descrevem, em partes, a conexão da participante com o mundo, com ela mesma e os boicotes que ela tende a fazer quando desacreditada de si.

As $\mathrm{PCH}$, como o toque da massagem, que acalma e direciona ao relaxamento, e a respiração consciente contribuíram para o 'start' da reconciliação entre a aluna participante e seu próprio corpo. Conforme afirma (5) Berge (1988), a respiração é o fio condutor para nos mostrar o ponto em que respiramos mal e insuficientemente, além de ser a primeira tomada de consciência corporal.

Outros apontamentos remetem à linguagem corporal e às percepções e descobertas da aluna participante em seu corpo. Antes, a reação imediata de não gostar de algo em si, como por 
O corpo que nada esquece: sensibilidade, percepção e memórias corporais Yara Aparecida Couto • Daniela Frizzon Zamboni

exemplo, quando solicitado para ela imaginar de olhos fechados uma árvore e a descrever: "[...] a minha árvore é aquela amarela com as folhas caindo" (NC4). Conforme as atividades transcorriam, ela esmiuçava uma percepção diferente da anterior: "após alguns minutos com as 'raízes' mais firmes no chão, ela falou "agora a cor é verde escuro" (NC4).

Outras experiências revelaram gestos desordenados e os movimentos desajeitados, pois, como afirma (5) Berge (1988), o "instrumento corporal" está desafinado, os tempos fortes se acumulam, e ele passa de uma ação para outra sem tempo de preparação. Mencionamos a prática de movimentos coordenativos 'sombra-espelho' a fim de explorar situações de ataque e defesa e assim perceber como fazer e o que fazer. Tais atividades mostraram uma desorganização no tempo para a ação, no entanto possibilitou que a aluna participante reorganizasse seu pensamento, estratégia, sentimento e ação.

Durante as reflexões acerca das experiências corporais sobre sua infância, a aluna participante revelou: "Não tive infância. Eu era criança e tinha que cuidar de outras ainda menores" (NC11). Por essa razão, surgiu a proposta de vivências que pudessem se tornar memória e sensação com sentido e significado em seu corpo. O convite era para explorar um cenário lúdico, descontraído e dançante de forma imaginativa e criativa:

Peguei dois bastões de madeira e perguntei "o que você acha que faremos com isso?" Ela respondeu "vou usar para ser o guarda da entrada do castelo" e se posicionou como tal. [...] Depois duelamos em nossos cavalos [...] Então lhe disse "agora você será a princesa que estará no baile desta noite" [...] E ela se vestiu com os retalhos de panos (NC11);

Então propus "vamos, agora é a sua vez". Primeiro sua reação foi dizer "mas eu não sei", então eu lhe disse "qualquer movimento, o que você quiser". Aos poucos, ainda tímida foi mexendo para um lado, levantando um pouco um pé, depois o outro [...] inseri 
O corpo que nada esquece: sensibilidade, percepção e memórias corporais Yara Aparecida Couto • Daniela Frizzon Zamboni

uma fita de cetim branca.O simples objeto acionou como quando se usa uma máscara no rosto e foi a ligação entre mim, ela e a dança (NC10).

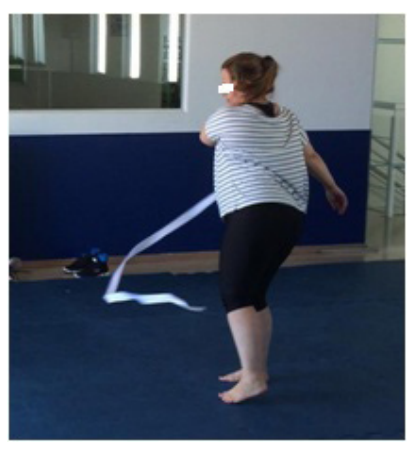

Fonte: Arquivo pessoal

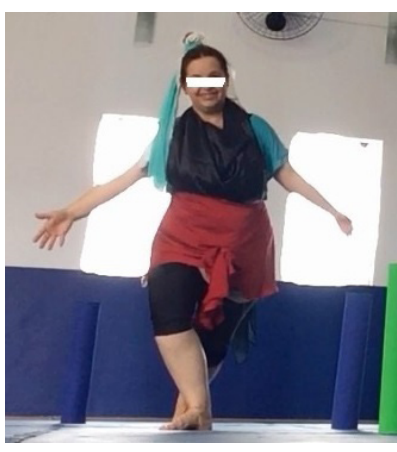

Fonte: Arquivo pessoal

Sobre essa experiência lúdica, a aluna participante refletiu: "É uma brincadeira que eu poderia ter feito e não fiz. Vi outra forma de fazer... Me sinto com vontade de me soltar mais. Que sensação de liberdade" (NC11).

No âmbito das memórias corporais e da sensibilidade, em um dos últimos encontros-aulas, a aluna participante, de olhos vendados, caminhou sobre diversas texturas com elementos naturais - folhas, sementes e grãos - e sentiu o cheiro e o sabor de alguns alimentos frescos.

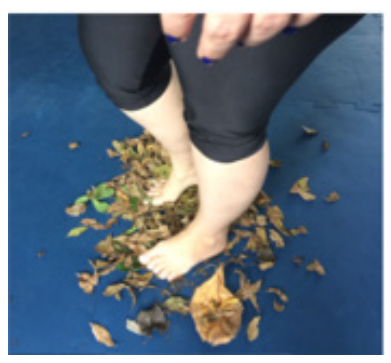

Fonte: arquivo pessoal

Sobre essa experiência ela relatou: 
O corpo que nada esquece: sensibilidade, percepção e memórias corporais Yara Aparecida Couto • Daniela Frizzon Zamboni

Parece que andei num espaço maior do que era, parece que dei várias voltas. Perguntei qual sensação ela identificou. A resposta: Sensação de liberdade... Andando longe e não era. Continuei: e o que mais você pode dizer? Ela respondeu: nunca tinha feito isso. Fechar os olhos e comer. Parece que você vai mais pelo olfato (NC14);

No último encontro-aula a proposta consistia em uma reflexão pessoal atrelada à capacidade de imaginação e criatividade. Em seguida, ela esculpiria com argila uma figura representativa, projetando expectativas para se tornar dali para frente uma muIher mais confiante, realizada e mais aquilo que julgasse ser meIhor para ela:

Ela exclamou: mas isso é só um pedaço de barro! Tirei uma semente que estava na sacola e lhe mostrei dizendo: o que você pode ver ao olhar para ela? Sua resposta foi: ela parece um coração. Pegou a semente e cheirou: tem um cheiro bom de café e cacau. Eu ainda falava: mas, ela não é só uma semente. Nela tem a árvore, as raízes, o tronco, os galhos, as folhas, as flores e frutos. Só é preciso preparar a terra fértil para que tudo isso aconteça... E você só precisa acreditar que nesta escultura pode haver uma conexão profunda com você mesma (NC15).

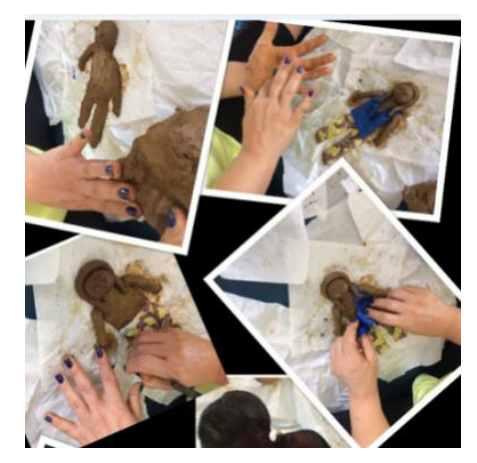

Quando ela finalizou sua escultura convidei-a para criar um lugar onde a "nova mulher" pudesse ir conhecer. Aqui foi impres- 
O corpo que nada esquece: sensibilidade, percepção e memórias corporais Yara Aparecida Couto • Daniela Frizzon Zamboni

cindível reafirmar a intenção de pensar, sentir e fazer e equilibrar sentido e significado com desejos e frustrações:

Agora você irá criar um lugar para esta "nova mulher". Você irá conectar aonde ela quer ir e poderá fazer do jeito que você quiser. [...] então ela criou um lugar com montanhas, rio e flores e disse: nunca fui a um lugar assim, gostaria de conhecer as montanhas. [...] Perguntei: o que demanda de você para fazer isso? Ela disse: vontade! Vontade de fazer e acreditar que você vai conseguir [...] Acho que posso conseguir as coisas. Eu estou animada (NC15).

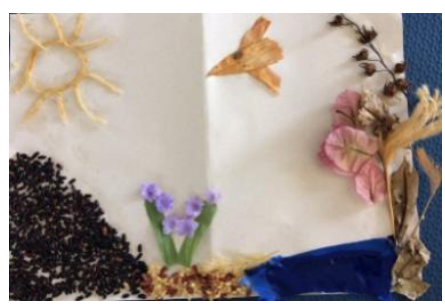

Fonte: arquivo pessoal

Quando a aluna participante sentiu-se parte dos processos vivenciados nas experiências corporais, assim como quando ela pode ter o sentimento de pertencimento, veio à tona a reflexão do processo construído:

Para falar a verdade cheguei descrente. Não achei que mexer joelho, o dedinho fosse mudar alguma coisa. Depois eu percebi que mudou. Quando comecei a me soltar mais. Sempre falo 'não vou conseguir', mas acho que consigo, não totalmente. Morro, quase morro (de dificuldade), mas tenho que dar o melhor de $\operatorname{mim}(\mathrm{NC15})$;

Eu gostei porque eu pude fazer outras descobertas sobre eu mesma... Coisas que eu não sabia [...] É como você falou "não existe não consigo. Se você tentar você vai conseguir. Eu consegui fazer algumas coisas que eu jamais pensei que fosse conseguir [...] O que você lembra primeiro quando pensa nas atividades que experienciou? Ela respondeu: Vou sentir falta de eu dançando com a fita (ENTREVISTA FINAL). 
O corpo que nada esquece: sensibilidade, percepção e memórias corporais Yara Aparecida Couto • Daniela Frizzon Zamboni

Substancialmente, um repertório maior de experiências foi registrado na memória de seu corpo, como, por exemplo, sentir o corpo na proposta de movimentar-se livremente, seus deslocamentos pelo espaço, imaginar, vibrar, sorrir, recordar da infância e, sobretudo, permitir-se a sensação "emocionante" - relatada pela aluna participante - ao dançar com uma fita e entregar-se à música, aos movimentos e ao seu corpo. Relembremos a NC 10 que remete à dança e a fita que firmaram um convite à autoestima, perceber-se e (re)descobrir-se num estado de alma convidativo para receber a alegria que o mundo oferece naquele momento em que ela esteve disponível para isso.

Ficaram evidentes nos momentos iniciais dos encontros-aulas que a primeira atitude da aluna participante foi se posicionar como incapaz e fora do convívio com outras pessoas frequentadoras da mesma academia. Contudo, algumas semanas após o encerramento do nosso trabalho, foi muito gratificante poder encontrá-la participando de um grupo de mulheres que buscava emagrecer, no qual ela aceitou se integrar e se dispor a encarar novos desafios.

\section{Conclusão}

Assumindo que o corpo nunca esquece nada (5) (BERTHERAT, 1977), este estudo de caso adentrou o universo das PCH e conciliou as experiências do corpo e suas memórias expressas em movimentos, ora possíveis de realizar, ora ausentes, que a aluna participante não reconhecia de início. Portanto, a partir da sua história de vida, seus desejos, suas frustrações, alcances e limites, foram constituídas novas percepções junto ao acesso de sentimentos e significados diante de cada atividade corporal vivenciada, além da descoberta de suas memórias corporais. E então, as dificuldades e/ou facilidades são percorridas em um processo de enfrentamento, no qual o corpo, ao (re)conhecer-se, é capaz de realizar o desconhecido, o novo, contribuindo para o processo de autoconhecimento. 
O corpo que nada esquece: sensibilidade, percepção e memórias corporais Yara Aparecida Couto • Daniela Frizzon Zamboni

A literatura oferece inúmeros textos que tratam de abordagens corporais que culminam no tema da sensibilidade e da percepção do corpo, suas dificuldades e seus processos de cura. Nesse sentido, (14) Vishnivetz (1995) afirma que o corpo consciente permite adquirir maior autoconfiança, liberar as percepções de sobrecarga profundas que limitam a amplitude de movimentos e reduzem a sensibilidade de si, do outro e do mundo.

As PCH vivenciadas conferiram à aluna participante o reconhecimento do próprio corpo através da atenção à respiração, do fluxo sanguíneo, do tônus e das amplitudes articulares. Assim como as percepções, sensações e emoções sentidas, engajadas pelo movimento corporal consciente, como quando estimulada pelo tato, pela música, por objetos e elementos naturais da terra, conforme as inspirações dos métodos da Antiginástica de (11) Bertherat (1977), as contribuições de (5) Berge (1988), (10) Ferreira (2000) e (6) Lorenzetto; Matthiesen (2008).

Este estudo concorda com a pesquisa de (17) Motta (2003) sobre a estranheza inicial quando o sujeito não associa os elementos da imagem corporal, movimento, pensamento e emoção como integradores de uma mesma personalidade. No entanto, mesmo quando a aluna participante se julgava incapaz de fazer os movimentos propostos, aos poucos, suave e tranquilamente, ela foi experimentando. Sentindo-se mais confiante, reconhecendo-se e tomando pertencimento de si, ela então pôde realizar os movimentos com liberdade, coragem que, por sua vez, foram se tornando mais firmes e coordenados.

É o que foi revelado pela participante com toda sua força, luta e seu enfrentamento de vida, ainda que de certo modo, em alguns momentos, ela se revelasse insegura, com dificuldades de envolvimento no cotidiano comum. Mas que, por outro prisma, percebe-se que todo processo vivenciado pela aluna foi iniciado quase como num mergulho, quando foi sendo traçado um caminho de possibilidades e de incertezas onde ela seguiu ultrapassando seus limites; uma vez que pôde reconhecer a si mesma e ao seu redor um mundo cheio de cor, sabor, texturas, afetos e tantas outras 
O corpo que nada esquece: sensibilidade, percepção e memórias corporais Yara Aparecida Couto • Daniela Frizzon Zamboni

sensações e percepções que se entrelaçaram aos desafios em que o viver exige dia após dia. Sem dúvida o novo só pode se revelar nessa presença e atenção, e mais, pelo pensamento e imaginação que leve à ação e traga para si sentido e significado.

Durante os encontros realizados com a aluna participante salientamos ter sido fundamental a presença de gestos que trouxessem o foco e a atenção para o presente, além de captar atentamente qualquer indício novo que viesse a contribuir para as suas descobertas. Além do mais, reconstruir ou descobrir novas possibilidades é uma prática indissociável às memórias corporais em sintonia com a condução e fluxo de um trabalho coeso e sensível, transparecendo segurança, calma e profundidade.

\section{Referências bibliográficas}

(1) OSTETTO, L. E. Educadores na Roda de Dança: formação - transformação. Tese (Doutorado). Faculdade de Educação UNICAMP, Campinas, 2006.

(2) HILLMAN, J. 0 pensamento do coração e a alma do mundo. Trad. Gustavo Barcellos. Campinas: São Paulo, Verus. 2010.

(3) HERMANN, N. Ética e estética: a relação quase esquecida. Porto Alegre: EDIPUCRS, 2005.

(4) PANIAGUA, R. S. M. O sentido em todos os sentidos. $33^{\mathrm{a}}$ Bienal de São Paulo - Afinidades afetivas, São Paulo, 2018.

(5) BERGE, Y. Viver o seu corpo: Por uma pedagogia do movimento. / Yvonne Berge; [tradução Estela dos Santos Abreu e Maria Eugênia de Freitas Costa; revisão Mônica Stahel M. da Silva]. -4. ed.-São Paulo: Martins Fontes, 1988.

(6) LORENZETTO, L. A.; MATTHIESEN, S. Q. Práticas Corporais Alternativas. Rio de janeiro: Guanabara Koogan, 2008.

(7) ROSZAK, T. A Contracultura: Reflexões sobre a sociedade tecnocrata e a oposição juvenil. Petrópolis: Vozes, 1972, 301 p. 
O corpo que nada esquece: sensibilidade, percepção e memórias corporais Yara Aparecida Couto • Daniela Frizzon Zamboni

(8) COLDEBELLA, A. de O. C. Práticas Corporais Alternativas: um caminho para a Formação em Educação Física. Dissertação de Mestrado. Rio Claro: Unesp, 2002.

(9) CESANA J. \& SOUZA NETO S. Educação física e práticas corporais alternativas: 0 trabalho com o corpo em questão. Motriz. Revista de Educação Física. UNESP, Rio Claro, v.14, n.4, p.462-470, out./dez. 2008.

(10) FERREIRA, L. A. Reencantando o corpo na educação física: uma experiência com as práticas corporais alternativas no ensino médio. 2000. 159 f. Dissertação (Mestrado em Ciências da Motricidade Humana) - Instituto de Biociências, Universidade Estadual Paulista, Rio Claro, 2000.

(11) BERTHERAT, T. $O$ corpo tem suas razões: antiginástica e consciência de si; com a colaboração de Carol Berstein; Traduzido do francês por Estela dos Santos Abreu. São Paulo: Martins Fontes, 1977.

(12) Impolcetto F. M. et al. As práticas corporais alternativas como conteúdo da educação física escolar. Pensar a Prática, Goiânia, v. 16, n. 1, p. 1-319, jan./mar. 2013.

(11) LELOUP, J.Y. O Corpo e Seus Símbolos: uma antropologia essencial./ Jean-Yves Leloup; Org. Lise Mary Alves de Lima.Petrópolis, RJ: Vozes, 2002 10ªd, 133p.

(14) VISHNIVETZ B. EUTONIA: educação do corpo para o ser / Berta Vishnivetz; tradução Benita Beatriz Canabrava. - São Paulo: Summus, 1995, $190 \mathrm{p}$.

(15) JUNG, C. G. A natureza da Psique. Petrópolis: Vozes, 2011. (16) LEVINE, P. A. O despertar do tigre: curando o trauma. São Paulo: Summus, 1999.

(17) MOTTA, R. Avaliação da imagem corporal durante o processo do Rolfing. Dissertação (mestrado em Educação Física) UNICAMP, Campinas, 2003.

(18) COUTO, Y. A. Arte na Educação: brincar, dançar, rodar... Tempos e espaços da infância. In: Intensidades da infância: 
O corpo que nada esquece: sensibilidade, percepção e memórias corporais Yara Aparecida Couto • Daniela Frizzon Zamboni

corpo, arte e o brincar. Org. PINHEIRO Maria do C. M. Goiânia: FUNAPE/DEPECAC, 2010. p. 178.

\title{
Publisher
}

\begin{abstract}
Universidade Federal de Goiás. Faculdade de Educação Física e Dança. Publicação no Portal de Periódicos UFG. As ideias expressadas neste artigo são de responsabilidade de seus autores, não representando, necessariamente, a opinião dos editores ou da universidade.
\end{abstract}

